discussion papers

FS IV $02-13$

Entry and Experimentation in

Oligopolistic Markets for Experience Goods

Daniel Krähmer

August 2002

ISSN Nr. 0722 - 6748
WISSENSCHAFTSZENTRUM BERLIN FÜR SOZIALFORSCHUNG

SOCIAL SCIENCE RESEARCH CENTER BERLIN 
Zitierweise/Citation:

Daniel Krähmer, Entry and Experimentation in

Oligopolistic Markets for Experience Goods, Discussion Paper FS IV 02-13, Wissenschaftszentrum Berlin, 2002.

Wissenschaftszentrum Berlin für Sozialforschung gGmbH, Reichpietschufer 50, 10785 Berlin, Tel. (030) 25491 -0 Internet: www.wz-berlin.de 


\title{
ABSTRACT
}

\section{Entry and Experimentation in Oligopolistic Markets for Experience Goods}

\author{
by Daniel Krähmer*
}

We investigate a two-period Bertrand market in which one seller introduces a new product of uncertain quality. The new product competes with an alternative good of known quality. Ex ante neither sellers nor consumers know the value of the new product. While consumers can learn their valuation by actual consumption (experimentation), sellers cannot observe experimentation outcomes. Thus, asymmetric information arises if the buyer experiments. As a result, the equilibrium is inefficient, and too little entry occurs.

Keywords: Entry, experimentation, asymmetric information, bandit problem, Bertrand competition

JEL classification: L13, L15, D82, D83

\section{ZUSAMMENFASSUNG}

\section{Markteintritt und Experimentation in oligopolistischen Märkten für Erfahrungsgüter}

Das Papier untersucht einen zweiperiodigen Bertrand-Markt, in dem ein Verkäufer ein neues Gut unbekannter Qualität einführt. Das neue Produkt konkurriert mit einem etablierten Produkt bekannter Qualität. Ex ante kennen weder die Verkäufer noch die Käufer den Wert des neuen Gutes. Ein Käufer kann seine Wertschätzung für das neue Produkt erfahren, indem er es ausprobiert (Experimentation). Die Verkäufer hingegen können nicht beobachten, ob der Käufer zufrieden war, wenn er das neue Gut konsumiert hat. Dadurch entsteht asymmetrische Information. Dies führt zu einem ineffizienten Gleichgewicht und zu zu geringem Markteintritt.

I would like to thank Helmut Bester, Jürgen Bierbaum, Kai A. Konrad, Roland Strausz, and two anonymous referees for helpful comments. 


\section{Introduction}

When a new good whose quality is uncertain is introduced, buyers may learn their valuation for the new good through actual consumption. Sell ers, however, can often not observe the consumers' private experience with the new good. If buyers purchase repeatedly, this gives rise to asymmetric information between sellers and buyers in later periods.

An example is opening a new restaurant. By trying it out, customers can learn whether they like the new cook's way of cooking. Generally, the restaurant's owner cannot observe directly, whether customers are satis..ed or not. The latter is also true for many experience goods for daily use, such as packaged shirts or canned drinks, durables whose utility for the consumer is only revealed over time, such as personal computers, particular types of services, for instance telecommunication services, or workers whose ability is unobervable ex ante. There are many other examples where the consumers' experience with the new good is not revealed to sellers. Indeed, it seems reasonable to argue that, in reality, this may be the rule rather than the exception.

The paper explores the consequences of this informational asymmetry for a duopolistic Bertrand market in a simple two period framework. In each period, a risky seller who initially introduces a new product competes with a safe seller who oxers an alternative good of known quality. The provider of the new product may be an entrant into a previously monopolistic market, or the new good may be a relaunch of an outdated design. A buyer can learn about her valuation of the new product by actual consumption. In this sense, the new product is an experience good (Nelson (1972)). The buyer's valuation for the safe good may be known from previous experience or from an exogenous recommendation, for instance, a consumer guide book.

From the perspective of the consumer, a seller is therefore one arm of a twoarmed bandit. On the one hand, by trying out the risky good (experimentation), the buyer learns about her valuation. On the other hand, the safe good provides a safe bene..t, but does not give any information about what her true taste for the new 
good is. That is, the buyer faces the well-known intertemporal trade-ox between exploration and exploitation.

The aim of the analysis is to determine when experimentation or, equivalently, entry occurs in equilibrium and to study the welfare properties of the equilibrium. We say that experimentation, or entry, occurs if the buyer chooses the risky seller in the ..rst period in equilibrium.

Our results are as follows: ..rst, the market equilibrium is in general inet cient, that is, social welfare in equilibrium is lower than social welfare in the social planner solution. Second, in equilibrium there is too little entry compared with the planner solution.

What drives these results is that experimentation outcomes are private information. For, if the buyer experiments in period 1, sellers cannot condition their prices on the buyer's valuation in the second period. Therefore, with positive probability, the buyer chooses the "wrong" seller in period 2, that is, the seller for whom her valuation is actually lowest. As a consequence, a welfare loss occurs.

The ined cient use of information reduces the bene.ts of the risky choice. Thus, the buyer's gross valuation for the risky seller in period 1 is reduced relative to the value of the risky arm in the planner solution. By contrast, the gross valuation for the safe seller is the same as the value of the safe arm in the planner solution. Yet, as a result of price competition, in equilibrium the buyer will choose the seller for whom she has the higher gross valuation. Therefore, if a planner is indixerent between the risky arm and the safe arm, the buyer in the market game will strictly prefer the safe seller. In this sense, there is too little entry in equilibrium.

M oreover, we discuss whether the buyer is willing to pay ex ante for information about the risky good. We shall identify a trade-ox between information and competition. A $n$ informed buyer enjoys an information rent relative to her uninformed counterpart, but information transforms the pricing game in such a way that sellers' market power is increased, competition is weakened, and higher prices are charged.

Our paper is a ..rst step towards extending the market experimentation literature to the case of privately observed experimentation outcomes. Several other papers (Bergemann/Välimäki (1996, 1997, 2001), K eller/Rady (2001)) study the 
relationship between entry, experimentation and oligopolistic competition, but in all of them experimentation outcomes are public information. Except for the ..nite time horizon, our model is closest to B ergemann/Välimäki ( 1996). B ecause experimentation outcomes are public information in their setting, in each stage sellers can condition their prices on the buyer's valuation. In contrast to our results, the market solution and the social planner solution are then identical.

Our paper is also related to the literature on multi-armed bandit problems. ${ }^{1}$ In the traditional bandit literature, the pay-ox characteristics of an arm are exogenously given. By contrast, in our model, as in Bergemann/Välimäki (1996), the bandit is rendered a player such that the bandit's pay-ox characteristics are subject to a player's choice. A ctive bandits are also considered in Bar-Isaak (2000). In his model, bandits are sellers who are privately informed about whether they provide high or low quality on average. Good sellers can signal ther type by accepting worse terms of trade than bad sellers and may thereby survive even when buyers experience long streaks of unfavourable experimentation outcomes.

The exp erience goods literature has mainly focussed on how the lemon's problem a la A kerl of, which arises in the context of non-contractible quality, can be overcome. The lemon's problem is typically mitigated when ..rms can build up a reputation², or when they can signal high quality ${ }^{3}$. In our model, the lemon's problem is not an issue because sellers are uninformed. Formally similar to our setting is a model by K im (1992), who studies the pricing behaviour of a monopolistic seller of an experience good who, as in our case, is uninformed about consumers' tastes and cannot observe experimentation outcomes. ${ }^{4}$

The paper is organized as follows. Section 2 presents the model. In section 3 the model is analyzed and the main results are derived. Section 4 concludes.

\footnotetext{
${ }^{1}$ T he seminal paper in the bandit literature is R othschild (1974), who considers the price setting behaviour of a local monopolist in the face of an unknown demand function. Berry/ Fristedt (1985) provides an introduction to bandit problems.

${ }^{2} \mathrm{See}$, e.g., the infuential article of $\mathrm{K}$ lein/Le er (1981). Further papers on reputation formation are Shapiro (1982, 1983a, 1983b), Liebeskind/ R umelt ( 1989).

${ }^{3}$ See, e. g., Allen (1984), Riordan (1986), Hoerger (1993).

${ }^{4}$ For a study on price and quality patterns of experience goods within a continuous time framework with a continuum of ..rms and consumers see also $\mathrm{G}$ ale/ R osenthal (1994).
} 


\section{The $M$ odel}

There are two time periods, $t=1 ; 2$. There are two sellers, a safe seller, $\mathrm{S}$, and a risky seller, R. In each period sellers produce each a unit of a good at zero cost. There is one buyer, $B$, who buys at most one unit of the two goods in each period.

In each period, sellers engage in price competition, and the buyer decides whether to buy a good and, if she does, from whom of the sellers.

B 's instantaneous valuation for (or her willingness to pay for, or her gross utility of) a good equals her expected instantaneous valuation for that good. ${ }^{5}$ From B's perspective, goods dixer with respect to their riskiness. While $B$ knows her valuation for the good delivered by $S$, she is ex ante ignorant about her true valuation for the good delivered by $\mathrm{R}$.

Suppose that B 's instantaneous valuation for S's good is known to all players to be equal to , $2[0 ; 1]$. By contrast, ex ante, B's true instantaneous valuation $x 2[0 ; 1]$ of R's good is known neither by sellers nor by $B$. However, players hold a common belief about B's instantaneous valuation for R's good, that is, from the perspective of the players, $B$ 's valuation for $R$ 's good is a random variable $X$ with values in $[0 ; 1]$. Let $F$ be the cumulative density function of $X$, and let $f=F 0$ be the corresponding probability density function. We assume that $X$ has ..nite .rst moment, and that $f$ is continuously dixerentiable and strictly positive on [0; 1]. Suppose that $F$ is common knowledge among all players.

$B$ can learn $x$ with certainty by consuming R's good. ${ }^{6}$ That is, the good of $R$ is an experience good, and, from the perspective of the buyer, each seller is an arm of a two-armed bandit. We say that experimentation, or entry, occurs when B chooses $\mathrm{R}$ in period 1 , and we call her observation $\mathrm{x}$ experimentation outcome. We assume that the experimentation outcome is B 's private information. That is, we interpret $X$ as $B$ 's subjective taste for $R^{\prime}$ 's good which cannot be observed by sellers. ${ }^{7}$

\footnotetext{
${ }^{5} \mathrm{R}$ isk-neutrality is assumed for simplicity of exposition. However, quasi-linearity is a crucial assumption.

${ }^{6}$ We could assume that the buyer gets an imperfect signal about her valuation. However, in a two-period setting this does not alter the logic of the model.

${ }^{7}$ The fact that sellers cannot observe experimentation out comes may seem inconsistent with the assumption that the buyer's valuation for the safe good is common knowledge. However, it would
} 
The timing is as follows. In period $1, R$ and $S$ simultaneously set prices $p_{1}$, and $q_{1}$ respectively. Given these prices, the buyer chooses whether to buy a good, and, if so, from whom of the sellers. If the buyer experiments, she learns her true instantaneous valuation $\mathrm{x}$ for the risky good, whereas in the other case she does not. Sellers observe consumption decisions, but they cannot observe experimentation outcomes. Call Al the information set reached if B experiments, and denote by $\mathrm{N}$ I the information set reached if $\mathrm{B}$ does not experiment. ${ }^{8}$ Here, the capitals refer to Asymmetric Information, and No Information respectively. In period 2, R and $S$ simultaneously set prices $p_{2}$, and $c_{2}$ respectively. Finally, given these prices, the buyer chooses whether to buy a good, and if so, from whom of the sellers.

We assume that players are Bayesian sequentially rational and that they play a perfect Bayesian Nash equilibrium. Since the time horizon is ..nite and to save in notation, we assume that players do not discount stage 2 pay-ous. Furthermore, to reduce case distinctions, we assume that $\mathrm{E}[\mathrm{X}] \cdot{ }^{9}{ }^{9}$

Remark: $F$ can be interpreted as the distribution of valuations for R's good among a continuum [0;1] of consumers where a consumer's location $\times 2[0 ; 1]$ is her valuation for R's good. Notice that this interpretation includes the case where consumers have heterogenous tastes not only for R's good but also for S's good. For what matters is only a consumer's dixerence $x i$, between the valuations for the two goods. If , is a continuous function of $x$, we obtain the same results by replacing $\mathrm{F}(\mathrm{x})$ by $\overline{\mathrm{F}}(\mathrm{x})=\mathrm{F}\left(\mathrm{x}_{\mathrm{i}},(\mathrm{x})\right)$ and assuming that the valuation for the safe seller's good equals 0 .

be easy to replace the safe good by a second risky experience good. This would only complicate the analysis without yielding signi..cant additional insights.

${ }^{8}$ To be precise, for each pair $\left(p_{1} ; q_{1}\right)$ of stage 1 prices there is one information set of type Al and one of $\mathrm{NI}$.

${ }^{9}$ If $E[X]>$, then the trade-ox between learning and instant grati..cation vanishes. From a social planner point of view, the risky alternative then dominates not only in terms of future but also in terms of current bene..ts. 


\section{A nalysis of the M odel}

As usual we solve for the perfect Bayesian Nash equilibria of the game by backward induction.

\subsection{The Second Stage}

\subsubsection{Information Set NI: U ninformed Players}

At information set $\mathrm{NI}$, no party has information about B's true valuation for R's good. The pricing game at $\mathrm{NI}$ is then a classical B ertrand game where $B$ 's valuation for R'S good is $E[X]$, and that for $S$ 's good is,. We assume the following tiebreaking rule for the case where $B$ is indixerent between $R$ and $S$ : if there is exactly one seller who could reduce prices slightly without making negative pro.ts, $B$ chooses that seller. In all other cases, if both or none of the sellers could reduce prices, B chooses S with probability 1.

This implies that the unique $B$ ayesian Nash equilibrium in pure strategies of the pricing game is given by $p=0 ; q=, i E[X],{ }^{10}$ and $B$ chooses $S$ in equilibrium. We note that $B$ 's expected pay-ox under informational setting $N I, u_{N}$, is

$$
u_{N I}=E[X]:
$$

\subsubsection{Information set AI: Informed Buyer, Uninformed Sellers}

At information set $A I$ the buyer has private information about her valuation $x$ of $X$ for $R$ 's good. ${ }^{11}$ To derive the equilibrium of the continuation game, we go through players' decisions in more detail.

Buyer's decision: Given prices $p$ and $q$, the buyer chooses $R$ if

$$
x \text { i } p>\text {, i } q \text {; }
$$

\footnotetext{
${ }^{10} \mathrm{In}$ this subsection we suppress time subscripts as far as possible and always mean period 2 prices when we use plain $p$ and $q$

${ }^{11}$ For a general account of price competition with an informed buyer and discrete valuations see Mosarini/O ttaviani (2001).
} 
and she chooses $S$ if the reverse inequality holds. If $B$ is indixerent, we use the same tie-breaking rule as above. ${ }^{12}$

Sellers' decision: Given B 's decision, the expected period 2 pro..ts of $R, 1 / R$, and of $S, 1 / 4$, are

$$
\begin{aligned}
1_{4}^{1 / R}(p ; q) & =p \phi P[X ; p>, i q] \\
& =p(1 ; F(,+p ; q)) ; \\
1 / 4(p ; q) & =q \Phi P[X ; p<, i q] \\
& =q F(,+p i q):
\end{aligned}
$$

The necessary ..rst order conditions for a Nash equilibrium of the pricing game are thus given by

$$
\begin{array}{r}
1 i F(,+p i q) \text { i } p q f(,+p i q)=0 ; \\
F(,+p i q) \text { i } q \phi f(,+p i q)=0:
\end{array}
$$

The suc cient second order conditions for a solution $(p ; q)$ of $(5),(6)$ to be an equilibrium are given by

$$
\begin{aligned}
& \text { i } \left.2 f\left(,+p_{i} q\right) \text { i } p \phi f{ }^{0},+p_{i} q\right)<0 ; \\
& \text { i } 2 f\left(,+p_{i} q\right)+q \phi f\left(,+p_{i} q\right)<0:
\end{aligned}
$$

Notice that this condition requires the curvature ( $\mathrm{f} O \mathrm{f}$ ) of $\mathrm{F}$ to be neither extremely large nor extremely small at a solution ( $p ; q)$ of $(5),(6)$. Intuitively, the curvature of $F$ measures the speed at which a seller's "market share" reacts to small price changes. If a seller's market share falls drastically through a price increase, then, since market shares add up to 1 , the other seller might pro..tably deviat eby reducing prices and thereby increasing sales drastically.

The latter cannot happen if the size of the curvature is bounded from below and above. A condition which sets a limit on the curvature of $F$, and which is suф cient for the existence of an equilibrium in pure strategies, is given in Bester (1992), p. 438. Bester shows that an equilibrium exists if $F$ is twice continuously dixer entiable

\footnotetext{
${ }^{12} \mathrm{~N}$ ot ice that $\mathrm{B}$ is indixerent at $\mathrm{Al}$ with probability 0 .
} 
on $(0 ; 1)$ and satis..es the following condition:

$$
i \frac{2}{z} \cdot i \frac{f^{0}\left(x_{i},\right)}{f\left(x_{i},\right)} \cdot \frac{2}{z} \quad \text { for all } \times 2(0 ; 1) ;
$$

where

$$
z=\max \frac{1}{F(,)} ;{\frac{1}{1}{ }_{i} F(,)}^{3 / 4}:
$$

From now on we shall assume that (9) holds. This implies that the pricing game has an equilibrium $(p ; q)$ in pure strategies. Notice that the equilibrium nœd not be unique. In what follows we shall assume that there is a focal equilibrium that sellers coordinate on and which the buyer understands is going to be played.

\subsubsection{The value of information}

The second stage of the game can be used to ask whether the buyer is willing to pay for information about the risky seller's good. Denote by $u_{A l}$ the buyer's expected pay-ox in the continution game following information set Al. Then the buyer's willingness to pay for information is given by the dixerence $u_{A I} i u_{N}$ between the pay-oxs when informed and when uninformed. Let $(p ; q)$ be an equilibrium of the pricing game at $\mathrm{Al}$, and denote by $\phi=p_{i} q$ the equilibrium price dixerential. Recall that at information se $\mathrm{NI}$, the buyer obtains gross utility, and pays a price $q^{N I}=(, i E[X])$. The willingness to pay for information can be written in terms of the dixerence in gross valuation and the dixerence in prices, that is,

$$
\begin{aligned}
u_{A 1} i u_{N 1}= & P[X>,+\phi](E[X j X>,+\phi] i,) \\
& +P[X<,+\phi](, i,) \\
& i i_{p P}[X>,+\phi]+q P[X<,+\phi] i q^{N \prime}{ }^{\Phi}:
\end{aligned}
$$

The ..rst two lines are the gross value of information. Whether this is positive or negative depends on the size of $\phi$. If $\phi$ is not too small, the gross value of information will be positive. The third line indicates a price exect: at information set $\mathrm{AI}$ both sellers have some market power while at information set $\mathrm{N} I$ they play a classical Bertrand game with $\ddagger$ at demand. Inserting $q^{N I}=(, i E[X])$ yields

$$
u_{A I} i u_{N I}=P[X>,+\phi](E[X j X>,+\phi] i E[X])
$$




$$
\begin{aligned}
& +P[X<,+\phi](, \text { i } E[X]) \\
& \text { i } \operatorname{pP}[X>,+\phi] \text { i } q P[X<,+\phi] \text { : }
\end{aligned}
$$

Whatever the buyer learns, that is, whether $X>,+\phi$ or $X<,+\phi$, the gross utility when informed is higher than net utility when uninformed. This can be seen as a form of favourable selection. However, due to sellers' increased market power at information set $\mathrm{Al}$, the buyer may have to pay a relatively high price when informed.

To see which exect dominates, consider the special case of a symmetric market. In a symmetric market, the share of buyers who have a higher valuation for $\mathrm{R}$ is the same as the share of buyers who have a higher valuation for $S$, that is, $F()=1=$,2 . If $F()=1=$,2 , equilibrium prices can be easily computed. Indeed, it follows from Proposition 1 that

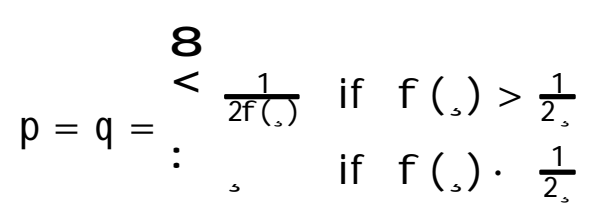

is an equilibrium of the pricing game. Equivalently, $p=q=\min ^{n} \frac{1}{2 f\left(f_{1}\right)} ;$, In particular, $\phi=0$. Hence,

$$
\begin{aligned}
u_{A I} i u_{N I}= & P[X>,](E[X j X>,] ; E[X / 2]) \\
& +P[X<,](, i E[X]) ; \min \frac{1}{2 f(,)} ;,:
\end{aligned}
$$

Thus, the overall exect depends on the size of $f($,$) . Indeed, the value of infor-$ mation increases in $f\left({ }_{0}\right)$. Intuitively, $f\left({ }_{2}\right)$ is a measure for sellers' market power at equilibrium prices. Sellers trade ox price reductions against increases in market share. If $f($,$) is large, B's valuation for R's good is relatively concentrated around$ , , and a relatively high number of consumsers can be attracted through price reductions. That is, competition is strong, and, as a result, prices are driven down in equilibrium. Thus, the gross favourable selection exect may outweigh the market power exect. On the other hand, if $f($,$) is small, sellers have relatively high mar-$ ket power, and prices are relatively high in equilibrium. A ccordingly, the value of information will be low. In this case, ex ante an uninformed buyer may be better ox than her informed counterpart, and therefore a buyer may not be willing to pay for information. 


\subsection{The First Stage}

As a benchmark case, we shall ...rst consider the social planner solution. Then we turn to the market allocation, and, ..nally, we compare them.

\subsubsection{The Social Planner Solution}

We consider the social planner solution in which the planner is as informed as the buyer in the market model, that is, if the planner strategy is to experiment in period 1, the planner can observe the experimentation outcome. This is just the solution to the two-armed bandit problem with one risky arm paying $x$ with density $f(x)$ and with one safe arm paying, with probability 1 . To break ties, we assume that the planner, if indixerent, selects the safe arm with probability $1 .^{13}$ Hence, given experimentation in $t=1$, the planner speci..es to choose $R$ in $t=2$ if the experimentation outcome $\mathrm{x}$ exceeds, and to choose $\mathrm{S}$ if $\mathrm{x}$. , Given no experimentation in $\mathrm{t}=1$, the planner speci..es to choose $\mathrm{R}$ in $\mathrm{t}=2$ if and only if $E[X]>$. Thelatter is however ruled out by assumption. ${ }^{14}$ Hence, experimentation in $t=1$ yields (..rst best) utility

$$
W R^{F B}=E[X]+P[X>,] \phi E[X j X>,]+P[X<,] \phi_{2} ;
$$

whereas selection of the safe arm in $t=1$ yields

$$
W S^{F B}=,+ \text { : }
$$

The social surplus in the planner solution is therefore

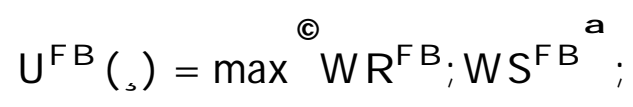

and the social planner strat egy prescribes experimentation if, and only if, W R ${ }^{F B}$ i $W^{F B}>0$. De.ne

$$
g(,)=W R^{F B} i W S^{F B}
$$

as the incentive to experiment in the social planner solution. Notice that $g$ is strictly decreasing in, ${ }^{15}$ Hence, there is a unique ..rst best cut-ox point, ${ }^{\mathrm{FB}}$ with $\mathrm{g},{ }^{\mathrm{FB}}{ }^{\Phi}=$ 0 , and experimentation is ec cient for all, $<, F B$.

\footnotetext{
${ }^{13} \mathrm{~T}$ his is consistent with the buyer's tie-breaking rule imposed in the market game.

${ }^{14}$ Otherwise the planner solution would always prescribe the risky arm in period 1.

${ }^{15}$ By Leibniz' rule it follows immediately that $\mathrm{g}^{0}<0$.
} 


\subsubsection{The M arket Solution}

We now turn to the market game when experimentation outcomes are private information to $B$. We shall show that-provided sellers do not charge the same prices in period 2-the market equilibrium is ined cient, and that, in a sense made more precise later, this ined ciency gives rise to under entry.

Before solving explicitely for stage 1 equilibrium behaviour, it is instructive to think directly about social surplus in the market game. Suppose, prices in period 1 are given, and $B$ has chosen a particular alternative in period 1 , that is, to experiment or not, be it optimal or not. Suppose further that an equilibrium of the respective continuation game is played. Now consider players' pay-oxs along that path in the game tree: due to quasi-linear utility B's expected (net) life-cycle utility equals B's expected gross life-cycle utility net of the expected life-cycle payments transferred to sellers. Sellers' combined expected life-cycle pro.ts are equal to B's expected life-cycle payments to sellers. Therefore, total social surplus along a particular play path is just equal to B's expected gross life-cycle utility along that path.

We now compute B's gross life-cycle utility along all possible paths conditional on optimal continuation in period 2 . If $B$ chooses $R$ in $t=1$, then she obtains gross instantaneous utility $E[X]$ in period 1 , and play reaches information set $A I$. In this case $B$ obtains gross period 2 utility

$$
P[X>,+\phi] \phi E[X j X>,+\phi]+P[X<,+\phi] \phi ;
$$

where

$$
\phi=p_{2} i q_{2}
$$

denotes the equilibrium price dixerential in period 2. Hence, B 's gross life-cycle utility from experimenting, $W R$, is given by

$$
W R=E[X]+P[X>,+\phi] \phi E[X j X>,+\phi]+P[X<,+\phi] \phi_{2}:
$$

If $B$ chooses $S$ in $t=1$, she obtains, in period 1 , and play reaches information set $\mathrm{N}$ I. In this case she stays with $\mathrm{S}$ and obtains, again. Therefore, B's gross 
life-cycle utility from choosing $S$ in period 1, WS, is given by

$$
\mathrm{WS}=,+, .
$$

As for el ciency, we now compare the social surplus in the market equilibrium with that in the social planner solution. For this purpose, suppose that an equilibrium of the market game exists and that $\phi \sigma 0$. Denote by $U^{M}$ the social surplus in the market equilibrium. That is, $U^{M}=W R$, if $B$ experiments in equilibrium, and $U^{M}=$ WS otherwise.

Consider ..rst the case in which $\mathrm{S}$ is chosen in $\mathrm{t}=1$ both in the market equilibrium and in the social planner solution. $T$ hen $U^{M}=W S=2$, and $U^{F B}=$ $W^{F B}=2$, Thus, $U^{M}=U^{F B}$.

Consider next cases in which $\mathrm{S}$ is chosen in $\mathrm{t}=1$ in the market equilibrium, but where the social planner strategy prescribes experimentation in $t=1$. Then $U^{M}=2$, and $U^{F B}=W R^{F B}$, WS $F B=2$, where the inequality holds because experimentation is ed cient in that case. Hence, $U^{F B}, U^{M}$.

Next, consider cases in which experimentation is chosen in $t=1$ in both the market equilibrium and in the social planner solution: Suppose, for instance, $\$>0$. Then, $\mathrm{B}$ 's choice in period 2 in the market dixers from that in the social planner solution in period 2 only when experimentation outcomes $x$ are in $(, ;,+\$)$. Notice that in the market game $B$ chooses $S$ in $t=2$ for all values $\times 2(, i,+\phi)$ although her period 2 valuation $x$ for $R$ 's good exceeds that for $S$ 's good. On the other hand, the social planner solution prescribes the seller for which $B$ has the higher valuation, that is, $R$. Therefore, with probability $P[,<X<,+\$]$ the buyer obtains only gross utility, in the market, whereas in the planner solution a gross utility of $E[X j,\langle X<,+\$]\rangle$, is attained. We state this ..nding in Proposition 3.

Proposition 1: Suppose $\phi \in 0$. Then $W R<W R^{F B}$ for all , $2[0 ; 1]$.

Proof: Suppose $\phi>0$. Then

$$
\begin{aligned}
W R \text { i WRFB }= & P[X>,+\phi] \phi E[X j X>,+\phi]+P[X<,+\phi] \phi, \\
& \text { i } P[X>,] \phi E[X j X>,]+P[X<,] \phi,
\end{aligned}
$$




$$
\begin{aligned}
= & P[X>,+\phi](E[X j X>,+\phi] i E[X j X>,+\phi]) \\
& +P[,+\phi>X>,](, i E[X j,+\phi>X>,]) \\
& +P[X<,](, i,) \\
= & P[,+\phi>X>,](, i E[X j,+\phi>X, \ldots]):
\end{aligned}
$$

The claim follows since, $<E[X j,+\phi>X>$, ]. For $\phi<0$, the same argument applies. $x$

Consider ..nally cases in which $\mathrm{R}$ is chosen in $\mathrm{t}=1$ in the market equilibrium, but the social planner strategy prescribes choosing $S$ in $t=1$. The latter implies that $U^{F B}=W S^{F B}$, $W R^{F B}$. But, with Proposition 1, this implies $U^{F B}>W R=U^{M}$ :

The last two paragraphs, particularly, show that the social planner surplus strictly dominates the social surplus in the market equilibrium whenever experimentation is prescribed by the social planner strategy, that is, whenever, $<$, FB. We summarize these observations in

Proposition 2: Suppose $\phi \quad 60$. Then $U^{M} \cdot U^{F B}$ for all, $2[0 ; 1]$ with the inequality being strict for all, $<, F B$.

The preceding considerations characterize the welfare implications of asymmetric information in terms of the price dixerential $\downarrow$. The following proposition characterizes $\phi$ in terms of the underlying distribution $\mathrm{F}$.

Proposition 3: $\phi \in 0() F(,) \in 1=2$, and $\phi<0() \quad F()>1=$,2 .

Proof: B y adding up sellers' ...rst order conditions (5), (6) and solving for $F(,+\phi)$, we obtain

$$
F(,+\phi)=1=2 ; \quad(1=2) \phi f(,+\phi):
$$

Thus, if $\phi=0$ solves (23), it follows that $F()=1=$,2 . Likewise, if $\phi<0$, then $F(,+\phi)>1=2$. Hence, since $F$ is increasing, $F()>,F(,+\phi)>1=2$.

On the other hand, if $F()=1=$,2 , then $\phi=0$ is a solution to (23). M oreover, 
if $F()>1=$,2 and $\phi, 0$, then the left hand side is strictly larger than $1=2$, and the left hand side is weakly smaller than $1=2$, a contradiction.

The proposition says that inet ciencies arise if, and only if, the market is not symmetric. If, say, $F()>1=$,2 , then after experimentation the buyer is more likely to have a higher valuation for $S$ than for $R$. This advantage enables $S$ to quote $a$ higher price than $\mathrm{R}$ so that $\phi<0$.

We can conclude that the market equilibrium, provided it exists, is ined cient for all, $<, F B$. The el ciency loss obtains because the buyer chooses the wrong seller with positive probability in period 2 of the market game. This is due to the presence of a non-zero price dixerential in period 2 which results from asymmetric information. In this sense, stage 2 prices fail to perform their role as informative signals of market conditions.

Remark: In the market model with public experimentation outcomes, Bergemann/Välimäki (1996) show that the market solution is identical with the social planner solution and thus el cient. In our simple model it can be easily seen why this is the case. If experimentation outcomes are public information, sellers can condition stage 2 prices on the experimentation outcome $x$. Then the unique pure strategy equilibrium of the continuation game following experimentation in period 1 is given by

$$
\begin{aligned}
& p_{2}(x)=\begin{array}{ll}
\stackrel{8}{<} x_{i}, & \text { if } x>, ; \\
0 & \text { if } x .
\end{array} \\
& q_{2}(x)=\stackrel{8}{<0} \text { if } x>, ;
\end{aligned}
$$

and $R$ will make sales in period 2 if $x>$, while $S$ will make sales in period 2 if $x$. . Therefore, the ed cient seller is always chosen in equilibrium, and there is no welfare loss. $x$

We now turn to the determination of the equilibrium. Notice that the pricing game 
in period 1 can be seen as a one-shot Bertrand game. However, unlike in the classic one-shot Bertrand game, period 1 prices need not be non-negative since sellers may make positive pro..ts in period 2. Intuitively, competition squeezes prices until one of the two sellers reaches a price below which he is better ox when not selling than when selling in period 1 . The other seller will then charge a price such that the buyer is just indixerent between sellers.

M ore precisely, for $i=R ; S$ denote by $1 / 2(A I)$, and $1 / 2(N I)$ respectively, seller i's period 2 pro..t in the continuation game following $\mathrm{Al}$, and $\mathrm{N} I$ respectively. Then, the smallest price $p_{1}$ which $R$ is willing to charge in period 1 and below which $R$ is better ox when not selling in period 1 is given by

$$
p_{1}+1 / 2(A I)=1 / 2(N I):
$$

Notice that $1 /$ R $_{2}(\mathrm{NI})=0$, thus, $p_{1}=\mathrm{i}^{1 / 2}(\mathrm{AI})$.

Likewise, the minimum price $b_{1}$ which $S$ is willing to charge in period 1 is given by

$$
\mathrm{b}_{1}+1 / \mathrm{S}(\mathrm{NI})=1 / \mathrm{S}(\mathrm{Al}):
$$

As above, we use the following tie-breaking rule for B : if exactly one seller sets his minimum price, B chooses the other seller. In all other cases, that is, if both or none of the sellers set their minimum price, $B$ chooses $S$.

Due to price competition, in equilibrium one of the sellers must charge his minimum price. Due to our tie-breaking rule this will be the seller who does not make sales in period $1 .{ }^{16}$

Suppose that B experiments in equilibrium. Then it is $S$ who charges his minimum price 1 , and $S$ is just indixerent betwen selling and not selling in period 1 . However, in equilibrium it must be that also $B$ is indixerent between the sellers. For otherwise $\mathrm{R}$ could raise period 1 price and increase his pro..ts. Therefore, since $B$ and $S$ are indixerent, it follows that the combined surplus $B$ and $S$ achieve together equals the surplus they would achieve if $B$ chose $S$, that is, the combined surplus WS $;$ 1/2 $(\mathrm{N} I)$ from not experimenting. Accordingly, R must extract the rest of the

\footnotetext{
${ }^{16}$ Except if both sellers charge their minimum price in equilibrium. In this case $\mathrm{S}$ makes sales in period 1.
} 
total surplus from experimentation. Hence, because $1 / 2(\mathrm{R} / \mathrm{N} I)=0, \mathrm{R}^{\prime}$ 's equilibrium life-cycle pro.t. conditional on selling in period 1 is WR i WS. In equilibrium, of course, for experimentation to obtain R's pro..t from selling in period 1 must be larger than R's pro.t. from not selling in period 1 . Hence, it must hold that $W R ; W S>0+1 / 2(N I)=0 .{ }^{17}$

By a similar argument, if $B$ does not experiment in equilibrium, then it must hold that WR i WS - 0 . Thus, B experiments in equilibrium if, and only if, $W R$; $W S>0$.

In other words, price competition in stage 1 implies that the buyer chooses the seller for whom her gross life-cycle utility is highest. The buyer's net willingness to pay for information, as discussed in section 3.1.1, is irrelevant in equilibrium insofar as sellers' stage 2 pro..ts will be refected in period 1 prices. If, say, the value of information is negative, the risky seller has to reduce prices in period 1 so as to compensate the buyer up front for her anticipated loss in period 2. A seller's competitive position in period 1 is therefore equal to the buyer's gross valuation.

To determine equilibrium prices, consider ...st the case in which $B$ experiments. Notice that R's life-cycle pro..t conditional on selling in period 1 is equal to period 1 price plus period 2 pro..ts in the continuation gamefollowing $A I$. Thus, $W R_{i} W S=$ $\mathrm{p}_{1}+1 / \mathrm{R}_{2}(\mathrm{Al})$. With $\mathrm{p}_{1}=\mathrm{i}$ 1/2 $(\mathrm{Al})$ it follows that the R's period 1 price equals

$$
p_{1}=W R ; W S+p_{1}:
$$

Likewise, if $B$ does not experiment in equilibrium, the period 1 price charged by $S$ is

$$
q_{1}=W S_{i} W R+q_{1}:
$$

We summarize our ..ndings in the following proposition.

Proposition 4: Suppose WR i WS $>0$. Then B experiments and entry occurs. Furthermore, sellers' equilibrium prices in period 1 are given by the pair

$$
p_{1}=W R ; W S+p_{1} ; \quad q_{1}=\phi_{1}:
$$

\footnotetext{
${ }^{17} T$ he strict inequality results from our tie-breaking rule.
} 
Suppose WR i WS - 0. Then B does not experiment and entry does not occur. Furthermore, sellers' equilibrium prices in period 1 are given by the pair

$$
p_{1}=p_{1} ; \quad q_{1}=W S ; W R+\phi_{1}:
$$

Though not stated explicitly, this is the unique perfect Bayesian Nash equilibrium of the market game.

We shall now use Proposition 4 to study when entry occurs in the market equilibrium compared to the social planner solution. We de.ne

$$
h(,)=W R \text { i WS }
$$

as the incentive to experiment in the market equilibrium or the risky seller's incentive to enter the market.

In order to compare the market solution to the social planner solution, we compare the functions $g=W R^{F B} i W S^{F B}$ and $h$. Since $W S^{F B}=W S$, the next statement follows immediately from Proposition 1.

Proposition 5: Suppose $\pitchfork \in 0$, then $h()<,g($, ) for all , $2[0 ; 1]$.

Proposition 7 implies that there is a market equilibrium cut-ox, ${ }^{\mathrm{ME}}<$, $\mathrm{FB}$ after which experimentation will not obtain in equilibrium. More precisely, let, ${ }^{\mathrm{ME}}=$ sup $f, j h()=,0 \mathrm{~g}$ be the largest root of $h$. Then it follows that $h()<$,0 for all ,$>, M E$, and $P$ roposition 5 implies that, $M E<, F B$.

Therefore, if , $2^{f}, \mathrm{ME}_{;}, \mathrm{FB}^{\mathbb{\phi}}$, the risky seller stays out of the market although optimally he should be chosen. A gain, this is because information is used inet ciently in period 2. This reduces the buyer's gross valuation for the risky seller in period $1, W R$, compared to the value of the risky arm in the planner solution, $W R^{F B}$. By contrast, the informational externality does not impair the gross valuation for the safe seller, WS. Therefore, the inec ciency weakens only the risky seller's competitive position but not that of the safe seller. As a consequence, if $2^{f},{ }_{M E} ;{ }^{F B}{ }^{\$}$, the entry price necessary to induce the buyer to experiment does not allow the risky seller to make positive pro..ts and he stays out of the market al- 
though entry is socially optimal. In this sense, there is too little entry in the market equilibrium.

We conclude this subsection with a summary of the results obtained and the case of uniform $X$.

Lemma 1: Suppose $\phi \epsilon 0$. Then the market equilibrium is inec cient for all

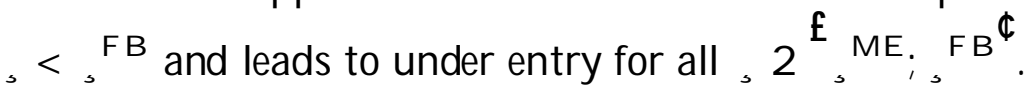

Example: Let X S U ([0; 1]). Then we have the following equilibrium values.

$$
\begin{aligned}
& h(,)=\frac{1}{2},{ }^{2} i 2,+\frac{17}{18} ; \quad g(,)=\frac{1}{2},{ }^{2} i \quad 2,+1 ; \\
& \text {, }{ }^{M E}=2 i^{P} \overline{19=9}_{1 / 4}^{10: 547 ;} \quad,{ }^{F B}=2 i^{P} \overline{2}_{1 / 40: 586 ;} \\
& 8 \\
& i \frac{1}{3},{ }^{2}+\frac{8}{9}, i \frac{4}{9} \text { if },<, M E
\end{aligned}
$$

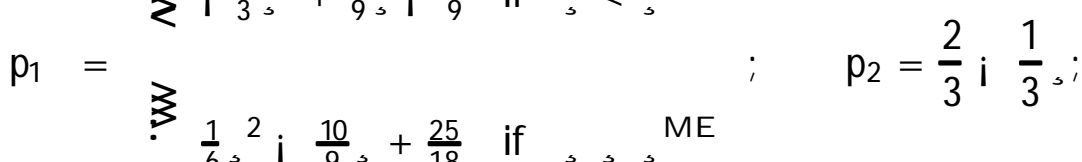

$$
\begin{aligned}
& 8 \\
& \frac{11}{18},{ }^{2} i,+\frac{8}{9} \text { if },<, M E \\
& q_{1}=\frac{3}{3} \quad q_{2}=\frac{1}{3}+\frac{1}{3},
\end{aligned}
$$

\subsubsection{Remark on Experimentation Incentives}

As mentioned above, in the planner solution the risky arm becomes less attractive as the valuation, for the safe alternative increases, that is, $\mathrm{g}^{0}<0$. However, we can not rule out in general that this may change in the market game. For the impact of an increase in, on the incentive to experiment W $R$; W $S$ can be disentangled into two exects. On the one hand, WS increases, and this makes experimentation less attractive. On the other hand, a change in, leads in general to a change in the stage 2 equilibrium, in particular in the price dixerential $\$$. If $j \phi j$ declines, experimentation becomes more attractive as the welfare loss in the market equilibrium under experimentation, $P[,+\phi>X, \ldots](, \mathrm{i} E[X j,+\phi>X, \ldots])$, declines. In this case, the additional surplus created increases the buyer's gross willingness to pay for 
the risky seller, W R, and thereby the incentive to experiment. In general, it could be possible for the second exect to dominate the .r.st exect.

\section{Conclusion}

The model presented in this paper is a ...rst step towards extending the market experimentation literature to the case of privately observed experimentation outcomes. This leads to asymmetric information and, in contrast to the public information setting, results in a welfare loss and in too little entry.

The qualitative conclusions of the analysis remain valid if the buyer is assumed to obtain only an imperfect signal about the risky alternative, if the buyer is assumed to be risk averse, if the safe al ternative is rendered risky as well, and if the number of sellers is increased. The model can easily be generalized along those lines. Essential for our argument is the assumption of quasi-linear utility. This somewhat restricts the relevant domain of the model. If the risks in question are very large, quasilinear utility might not be an adequate representation of the trade-o the buyer faces. Nevertheless, we conjecture that our qualitative conclusions still hold for more general utility functions because, intuitively, the introduction of general utility would essentially amount to a transformation of the random variable $X$.

What is, however, crucial for our results is the restriction to a two-period time horizon. If for instance the time horizon is extended to three periods, the logic of the model alters considerably. Consider the decision of an informed buyer at the second stage. With three periods, this decision contains an additional strategic element since the buyer's choice reveals information about her valuation which can be utilized by sellers for price setting in period 3. In particular, there will be a ratchet exect. Suppose the buyer learns in period 1 to have a high taste for the risky seller's good. On the one hand, this should increase the incentive to choose the risky seller in period 2. On the other hand, however, if she chooses the risky seller in period 2, the risky seller learns about the buyer's high valuation and can therefore set a high price, that is, rip ox the buyer in the terminal period. This reduces the buyer's incentive to choose the risky seller in period 2 . We have not 
looked at how this exect feeds back to the experimentation incentive in the initial period, and we leave a full account of the problem to future research.

In a further direction of future investigation points the literature on multi-player bandit games in which several players play the same bandit and can observe the pay-oxs obtained by other players as pioneered by Bolton/Harris (1999). Bergemann/Välimäki (2000) study a multi-player bandit game in a market context in which bandits set prices. Kamp (1998), in an experience good context similar to ours, considers a two-period model with a monopolist in which ..rst period buyers transmit information about their experience to second period buyers. Extensions and variations of these approaches could shed more light on questions about how the decentralized spread of information, like word-of-mouth communication or local rumours, may axect the performance of experience goods markets.

\section{R eferences}

[1] Allen, F. (1984): "Reputation A nd Product Quality," RAND J ournal of E conomics, 15, 311 - 327.

[2] Bar-Isaak, H. (2000): "Good Advisers Survive Despite Bad Luck," Mimeo, LSE.

[3] Bergemann, D., Välimäki, J . (1996): "Learning A nd Strategic Pricing," Econometrica, 64, 1125 - 1149.

[4] Bergemann, D., V älimäki, J . (1997): "M arket Dixusion With T wo-Sided Learning," RAND J ournal of Economics, 28, 773795.

[5] Bergemann, D., V älimäki, J . (2000): "Experimentation In Markets," Review of E cononomic Studies, 67, 213 - 234.

[6] Bergemann, D., Välimäki, J . (2002): "Entry And Vertical Dixerentiation," J ournal of Economic Theory, forthcoming.

[7] Berry, D. A., Fristedt, B. (1985) : Bandit Problems. New York, Chapman and Hall. 
[8] Bester, H. (1992): "Bertrand Equilibrium In A Dixerentiated Duopoly," International E conomic Review, 33 (2), 433 - 448.

[9] Bolton, P., Harris, C. (1999): "Strategic Experimentation," Econometrica, 67, 349-374.

[10] Gale, D., Rosenthal, R. (1996): "Price And Quality Cycles For Experience Goods," RAND J ournal of E conomics, 25 (4), 590 - 607.

[11] Hoerger, T. (1993): "Two-part Pricing For Experience Goods In The Presence Of Adverse Selection," International J ournal of Industrial Organization, 11, $451-474$.

[12] Kamp, B. (1998): "Experience Dependent Information Dixusion And Product Quality," Economic Inquiry, 36 (1), 161 - 170.

[13] Keller, G., Rady, S. (2001): "Price Dispersion And Learning In A Dynamic Dixerentiated-Good Duopoly," CEPR Discussion Paper No. 2919.

[14] Kim, J . (1992): "Experience Goods, Expectations And Pricing," Economic Record, 68 (200), 7 - 15.

[15] K lein, B., Le er, K. (1981): "T he Role Of Market Forces In A ssuring C ontractual Performance," J ournal of P olitical E conomy, 89, 615 - 641.

[16] Liebeskind, J ., Rumelt, R. (1989): "Markets For Experience Goods W ith Performance Uncertainty," RA ND J ournal of E conomics, 20 (4), 601 - 621.

[17] Moscarini, G., Ottaviani, M. (2001) "Price Competition For An Informed Buyer," J ournal of Ecnomic Theory, 101 (2), 457 - 493.

[18] N elson, P. (1972): "Information And Consumer Behavior," J ournal of Political E conomy, 78, 311 - 329.

[19] Riordan, M. (1986): "M onopolistic Competition With Experience Goods," Q uarterly J ournal of Economics, 101 (2), 265 - 279. 
[20] Rothschild, M. (1974): "A T wo-armed B andit Theory Of Market Pricing," J ournal of Economic Theory, 9, 185-202.

[21] Shapiro, C. (1982): "Consumer Information, Product Quality And Seller Reputation," Bell J ournal of Economics, 13, 20 - 35.

[22] Shapiro, C. (1983a): "Optimal Pricing Of Experience Goods," B ell J ournal of E conomics, 14 (2), 497 - 507.

[23] Shapiro, C. (1983b): "P remiums For High Quality Products As Returns To Reputations," Quarterly J ournal of Economics, 98, 659 - 679. 